\title{
Downstream coronary effects of drug-eluting stents
}

\author{
Richard A. Krasuski, MD, George M. Cater, MSE, Ganesh P. Devendra, MD, Kathy Wolski, MPH,
} Mehdi H. Shishehbor, DO, MPH, Steven E. Nissen, MD, Carlos Oberti, MD, and Stephen G. Ellis, MD Cleveland, OH

Background Antiproliferative agents used in drug-eluting stents (DES) attenuate atherosclerosis, yet DES implantation has been linked to endothelial dysfunction. The downstream effects of DES on new lesion formation have not been previously directly examined. We sought to compare the development of de novo stenoses and need for treatment in the downstream coronary vessel of patients treated with DES or a bare-metal stent.

Methods Angiographic images and procedural information were prospectively collected on 463 adults who underwent implantation of a single stent in a proximal coronary artery, had an appropriate control vessel for comparison, and subsequently returned for intervention. Propensity matching identified 89 pairs of patients. End points were defined as angiographic identification of a de novo stenosis or need for secondary intervention in the downstream vessel within 12 months of initial intervention.

Results In the overall $(P<.01)$ and propensity-matched cohort $(P=.01)$, there was reduced risk of new lesions downstream to DES. No difference was seen in respective control vessels $(P=.14$ and $P=.99)$. A reduced need for downstream intervention with DES was seen in both the overall $(P=.01)$ and propensity-matched cohorts $(P=.04)$. No difference was seen in the control vessels $(P=.98$ and $P=.36)$. Multivariate proportional hazards modeling of known atherosclerosis risk factors identified stent type as the sole predictor for downstream lesions $(P<.01)$ and downstream events $(P=.02)$.

Conclusions Patients receiving DES appear less likely to develop downstream stenoses and events compared with patients receiving bare-metal stents, suggesting beneficial downstream drug delivery. (Am Heart J 201 1;0:1-8.e1.)

Percutaneous coronary intervention (PCI) remains a delicate balance between controlled mechanical disruption and the competing forces of elastic recoil, inflammation, and cell proliferation. ${ }^{1,2}$ Although stents have essentially eliminated vessel reocclusion, restenosis has remained a costly and highly morbid problem. ${ }^{3-5}$ Mechanical disruption of the endothelium and media appears to trigger intimal and vascular smooth muscle proliferation around the stent surface, and borrowing from the oncologic armamentarium, cell-cycle inhibition has been shown to inhibit this process. ${ }^{6,7}$ Coating stents with antiproliferative agents allows targeted delivery to the region of local trauma. ${ }^{8} \mathrm{~A}$ few studies have also shown similar reductions in in-stent restenosis with systemic administration of cell-cycle inhibitors. ${ }^{9,10}$

From the Department of Cardiovascular Medicine, The Cleveland Clinic, Cleveland, $\mathrm{OH}$. Submitted August 2, 2011 ; accepted August 2, 2011.

Reprint requests: Richard A. Krasuski, MD, Department of CV Medicine, Desk J2-4, Cleveland Clinic Foundation, 9500 Euclid Ave, Cleveland, OH 44195.

E-mail: krasusr@ccf.org

0002-8703/\$ - see front matter

(c) 2011 , Mosby, Inc. All rights reserved.

doi:10.1016/i.ahj.2011.08.001
Currently, guidelines supporting which type of stents should be used under what circumstances remain controversial. $^{11,12}$ Although drug-eluting stents (DESs) clearly reduce the risk of restenosis, they may also increase the risk of stent thrombosis, a potentially fatal event, particularly in patients who interrupt subsequent antiplatelet therapy. ${ }^{13-15}$ Recent studies also suggest that DESs may result in endothelial dysfunction manifested through impaired vascular responsiveness in the downstream vessel as well as contributing to late stent thrombosis through neoatherosclerosis. ${ }^{16-18}$ However, several studies also suggest that cell-cycle inhibitors may possess antiatherogenic properties. ${ }^{19-23}$ Although published data are conflicted, it appears that overall outcomes, including target vessel revascularization rates, are slightly more favorable in patients receiving DES, although this has to be weighed against higher stent costs and the necessity for prolonged, uninterrupted antiplatelet therapy. ${ }^{24,25}$ In addition, there are differences in the rates of target vessel versus target lesion revascularization rates, implying that pathologic processes are modified in other regions of the stented coronary. ${ }^{26,27}$

Downstream drug delivery from a stent-based platform has recently been demonstrated by one of the authors (C. Oberti). ${ }^{28}$ It is therefore reasonable to expect drug 
Figure 1

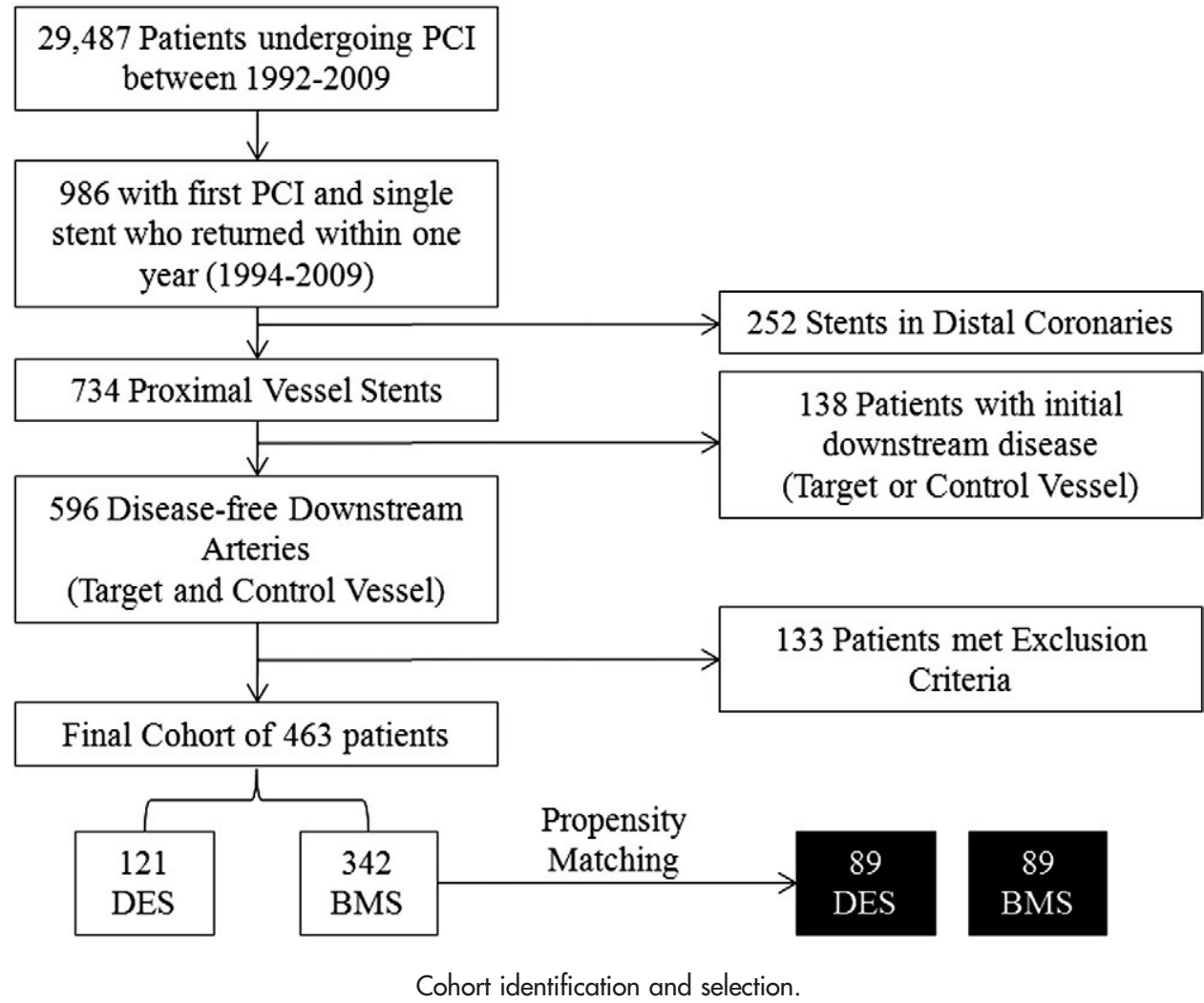

delivery to the distal vessel in patients receiving proximal DES. No previous studies have directly addressed the effect of eluted drug on downstream plaque formation in humans. Based on the improved clinical outcomes in target vessels realized with DES, the premise of downstream drug delivery, and the potential for antiatherogenic properties of cell-cycle inhibitors, we sought to examine the impact of downstream drug delivery on new lesion development and clinical events in patients having undergone coronary artery stenting.

\section{Methods}

\section{Study population}

The Cleveland Clinic Interventional Cardiology Registry was developed in 1992 with institutional review board approval for the purpose of collecting data on all patients undergoing PCI. Information on 29,487 patients was prospectively collected between January 2, 1992, and June 30, 2009, including angiographic findings, interventions performed, procedure outcomes, comorbidities, and cardiovascular risk factors. In addition, the type of stent implanted and prior coronary intervention were also collected. Coronary anatomy identification was standardized through the use of the National Cardiovascular Data Registry CathPCI Registry Coronary Artery Segment Diagram v. 4.0.
A query of this database identified 986 patients who underwent initial PCI to a single vessel with a single stent placed and then returned for a second PCI (allowing for comparison of coronary anatomy) within a year (Figure 1). Indication for secondary PCI was clinical suspicion for continued atherosclerotic disease. Of this population, we identified 734 patients who had stents implanted in the proximal right coronary artery, proximal left anterior descending coronary artery, proximal left circumflex, mid right coronary artery, mid left anterior descending coronary artery, and mid left circumflex; these locations facilitated the examination of downstream effects. Of these patients, 596 had no angiographic lesions downstream of the initial stent at the time of implantation with an accompanying control artery free from angiographic stenosis at the time of intervention (based on a standardized estimation of downstream vessel length, shown in the online Appendix Supplementary Table 1). Freedom from downstream stenoses on initial angiography was confirmed by blinded assessment in a subset of the catheterization films by an experienced angiographer (RAK).

A total of 133 patients were excluded for either chronic total occlusion at the time of initial intervention, procedural failure, prior bypass grafting to the stented artery, and intentionally staged procedures. The final cohort thus consisted of 463 patients who were angiographically free of stenosis in both the vasculature downstream from the implanted stent and in the respective territory of the control artery at the time of initial intervention. Among this cohort, 121 patients had undergone 
DES implantation, and 342 patients had bare-metal stent (BMS) implantation. The DES cohort only included stents designed to deliver antiproliferative agents to the local endothelium and consisted of 81 sirolimus-eluting stents and 40 paclitaxel-eluting stents. The BMS cohort consisted of all other BMSs. Propensity matching was performed on the entire cohort and identified 89 DES and 89 matched BMS patients.

\section{Definition of time to event (lesion/intervention)}

A downstream intervention was defined as the need for mechanical revascularization of the target vessel within 12 months of the initial interventional procedure. These interventions were performed on de novo lesions located in an arterial segment receiving direct blood supply through the previously stented territory. Revascularizations of in-stent restenosis or lesions proximal to the stented segment were excluded. This principle was modified to apply to the control artery, where the downstream intervention segment received blood through the analogous control vessel segment. Subsequent mechanical revascularizations included balloon angioplasty, stenting, rotablator, or cutting balloon; the intervention was counted as a single event, regardless of the number of lesions requiring treatment in the downstream segment.

A downstream de novo lesion was defined by angiographic evidence of new obstruction in the target vessel within 12 months of the initial interventional procedure. A $>25 \%$ stenosis was deemed clinically recognizable as a de novo lesion. In-stent restenosis and distal stent edge lesions $<5 \mathrm{~mm}$ from the stent were excluded. Downstream lesions were radiographically identified by a staff interventionalist using standard views and included stenoses that did not result in percutaneous therapy.

\section{Determination of downstream territory}

Downstream territory determination was standardized in both the control and target vessels through a segment algorithm developed from the National Cardiovascular Data Registry CathPCI Coronary Segment Diagram (online Appendix Supplementary Figure 1). All analyses of downstream interventions and lesions used this consistent algorithm, and any ambiguous vessels were not included. Time to intervention was determined as the difference in time between the first and second PCI. Of the 463 patients analyzed, 61 required downstream target-vessel interventions, and 21 required downstream control vessel interventions. Sixty-eight patients developed downstream target vessel lesions, and 32 patients developed downstream control vessel lesions.

\section{Statistical analyses}

The purpose of the study was to determine the hazard of requiring downstream intervention as well as de novo lesion formation in a group of patients who were originally angiographically free from downstream disease and then required a secondary intervention primarily because of recurrence of symptoms. Continuous variables are presented as mean \pm SD. Differences in baseline and angiographic characteristics of the unmatched cohort were compared using 2-sample $t$ test for continuous variables and the $\chi^{2}$ test or Fisher exact test where appropriate for categorical variables. Comparison in the matched cohort was done with a paired-sample $t$ test for continuous variables and the Cochran-Mantel-Haenszel $\chi^{2}$ test for count data. Unadjusted time-to-event data in the control and target vessels were analyzed and represented using KaplanMeier curves at a 12-month cutoff. In addition, multivariable Cox proportional hazards regression was used to examine the association between the type of stent used and the need for downstream target vessel revascularization using the log-rank test. Established risk factors for the development of coronary artery disease were included in the model to adjust for possible confounding. These included age, body mass index (BMI), systolic blood pressure, and history of diabetes, dyslipidemia, tobacco, or premature familial coronary artery disease.

In addition to the analysis performed on the entire cohort, propensity matching was also performed. The propensityscored cohort was matched based on age, gender, race, BMI, history of hypertension, history of dyslipidemia, history of myocardial infarction, angina on admission, positive stress test, urgency of procedure, vessel size, and American College of Cardiology lesion score. Development of events in BMS- and DES-matched cohorts were then analyzed and represented in Kaplan-Meier survival curves using log-rank tests. Statistical analysis was performed in JMP 8.0 and SAS version 9.1 (SAS Institute Inc, Cary, NC). All tests were 2 tailed with $P<.05$ considered significant.

\section{Results}

\section{Baseline characteristics of overall cohort}

Risk factors for atherosclerotic disease, including age (62 \pm 12 vs $64 \pm 11$ years, $P=.28$ ), mean systolic blood pressure $(134 \pm 25$ vs $138 \pm 24 \mathrm{~mm} \mathrm{Hg}, P=.17)$, prior smoking history (60\% vs $61 \%, P=.82)$, BMI $\left(29.6 \pm 6.1\right.$ vs $28.6 \pm 5.2 \mathrm{~kg} / \mathrm{m}^{2}$, $P=.07)$, hyperlipidemia (70\% vs $79 \%, P=.06$ ), diabetes (35\% vs $33 \%, P=.82$ ), and premature family history of coronary artery disease (36\% vs $28 \%, P=.15)$ were similar among BMS and DES groups, respectively (Table I). Patients receiving DES were equally likely to be treated for hypertension $(59.5 \%$ vs $55.3 \%, P=.19)$ but more likely to be on lipid-lowering medications (67.8\% vs 40.4\%, $P<.01)$.

\section{De novo downstream lesion identification}

The identification of downstream lesions at the time of the subsequent intervention was analyzed in both target and control vessels. Kaplan-Meier analysis was performed on the entire cohort and the propensity-matched cohort (Figure 2). Implantation of a DES compared with a BMS was associated with reduced risk of new lesion development in the vessel downstream of the stent for both the entire cohort (RR $0.39,95 \%$ CI $0.19-0.73, P<.01$ ) as well as the propensity-matched cohort (RR $0.36,95 \%$ CI 0.14 $0.82, P=.01)$. There was no difference in the development of new control vessel lesions in patients receiving BMS or DES in the overall cohort (RR 0.53, 95\% CI $0.20-1.21, P=.14$ ) or in the propensity-matched cohort (RR 0.99, 95\% CI 0.26-4.07, $P=.99$ ). Multivariable Cox proportional hazards regression of the target vessel new lesion development for the entire cohort was associated with a significantly reduced hazard for the 
Table I. Baseline demographic data of patients by implanted stent

\begin{tabular}{|c|c|c|c|c|c|c|}
\hline Demographic & $\begin{array}{c}\text { Overall BMS } \\
(n=342)\end{array}$ & $\begin{array}{c}\text { Overall DES } \\
(n=121)\end{array}$ & Overall $P$ & $\begin{array}{l}\text { Matched BMS } \\
(\mathbf{n}=\mathbf{8 9})\end{array}$ & $\begin{array}{l}\text { Matched DES } \\
\quad(n=89)\end{array}$ & Matched $P$ \\
\hline Age $(y)$, mean $\pm S D$ & $62.2 \pm 12.4$ & $63.5 \pm 10.8$ & .28 & $65.2 \pm 10.4$ & $63.5 \pm 10.9$ & .28 \\
\hline Female (\%) & 36.8 & 39.7 & .59 & 37.1 & 42.7 & .47 \\
\hline Systolic blood pressure, mean \pm SD & $134.3 \pm 25.2$ & $137.8 \pm 23.6$ & .17 & $133.4 \pm 26.2$ & $139.3 \pm 25.3$ & .17 \\
\hline Race (\%) & & & .73 & & & .49 \\
\hline White & 81.3 & 79.3 & & 82.0 & 79.8 & \\
\hline Black & 14.6 & 17.4 & & 14.6 & 19.1 & \\
\hline Other & 4.1 & 3.9 & & 3.4 & 1.1 & \\
\hline History of angina (\%) & 76.0 & 71.1 & .33 & 70.8 & 71.9 & .88 \\
\hline Smoking history (\%) & 59.9 & 61.2 & .82 & 60.7 & 60.7 & 1.0 \\
\hline Body mass index $\left(\mathrm{kg} / \mathrm{m}^{2}\right)$, mean $\pm \mathrm{SD}$ & $29.6 \pm 6.1$ & $28.6 \pm 5.2$ & .07 & $28.2 \pm 4.8$ & $28.7 \pm 5.3$ & .51 \\
\hline Hyperlipidemia (\%) & 69.9 & 79.3 & .06 & 71.9 & 77.5 & .40 \\
\hline Diabetes (\%) & 34.5 & 33.1 & .82 & 30.3 & 29.2 & .86 \\
\hline Premature family CAD history (\%) & 35.7 & 28.1 & .15 & 28.1 & 29.2 & .87 \\
\hline Mean coronary jeopardy score & $2.2 \pm 1.1$ & $2.3 \pm 0.9$ & .40 & $2.0 \pm 0.9$ & $2.2 \pm 0.9$ & .29 \\
\hline Hypertension (\%) & 65.5 & 83.5 & $<.01$ & 78.6 & 78.6 & 1.0 \\
\hline
\end{tabular}

development of new downstream lesions in patients receiving DES, which in fact was the only significant predictor in the model (HR 0.39, 95\% CI 0.19-0.75, $P<.01$ ) (Table II).

\section{Downstream interventions performed}

The need for downstream interventions was analyzed in the target and control vessels. Kaplan-Meier analysis was performed on the entire cohort and the propensitymatched cohort (Figure 3). There was significantly reduced risk for requiring downstream intervention in the DES-treated target vessel compared with the BMS target vessel for both the entire cohort (RR $0.45,95 \%$ CI $0.21-0.85, P=.01)$ and the propensity-matched cohort (RR $0.41,95 \%$ CI $0.16-0.97, P=.04$ ). There was no difference in the need for downstream interventions in the control vessels of those patients receiving DES compared with the BMS for the overall cohort (RR 0.99, 95\% CI $0.35-2.45, P=.98)$ as well as the propensitymatched cohort (RR 2.1, 95\% CI 0.44-14.8, $P=.36$ ). Multivariable Cox proportional hazards regression of the target vessel for the entire cohort was associated with a significantly reduced hazard for the need for downstream interventions in the DES population, again as the only significant predictor in the model (HR $0.47,95 \%$ CI 0.22 $0.90, P=.02$ ) (Table II).

\section{Discussion}

Patients who undergo implantation of DESs appear to have a significantly lower likelihood of developing downstream coronary stenoses than patients who have BMSs implanted. Furthermore, PCIs are also substantially less likely to be necessary in the downstream vessels. These findings were consistent despite multiple analytic techniques, including propensity analysis and multivariate proportional hazards modeling. Although we were unable to absolutely identify the reason for these reductions, downstream delivery of antiproliferative (cell-cycle inhibiting) medications appears to be a very plausible explanation. Although this result is not expected with respect to a variety of studies demonstrating endothelial dysfunction in vessels treated with DES and neoatherosclerosis of the target lesion, the notion that antiproliferative agents could have an atheroprotective effect is not without precedent. ${ }^{16,17}$

Multiple studies have demonstrated the atherosclerotic attenuation of sirolimus in Apolipoprotein E-deficient mice and human vascular smooth muscle cells. ${ }^{19-22} \mathrm{~A}$ variety of studies investigating coronary artery disease in heart transplant patients, who have baseline endothelial dysfunction, have shown that antiproliferatives such as sirolimus attenuate the rate of atherosclerotic progression. ${ }^{29,30}$ In addition, paclitaxel is a well-known immunomodulatory agent and has also been associated with atherosclerotic regression in animal models, as well as reduced inflammation in stented porcine arteries. ${ }^{23,31}$ Furthermore, given that the product labeling and pharmacokinetic studies in sirolimus-eluting stents describe serum detectability of antiproliferative agents for over 2.5 weeks and an estimated 3 month elution period after implantation (depending on stent type), one would expect these drugs to have long-term effects on the downstream vascular bed. ${ }^{32-34}$ As confirmation of prolonged biologic effect, neointimalization, the process by which the stent is covered by new endothelium postdeployment, appears to be delayed up to 12 months in sirolimus-eluting stents. ${ }^{35}$ Mathematical modeling suggests that the downstream coronary bed of sirolimus stents may see medication doses approximately 8 times higher than concentrations used to prevent organ rejection after transplantation (see the online Appendix Supplementary Calculation). Such doses may be necessary because similar beneficial effects on stenoses were 


\section{Figure 2}

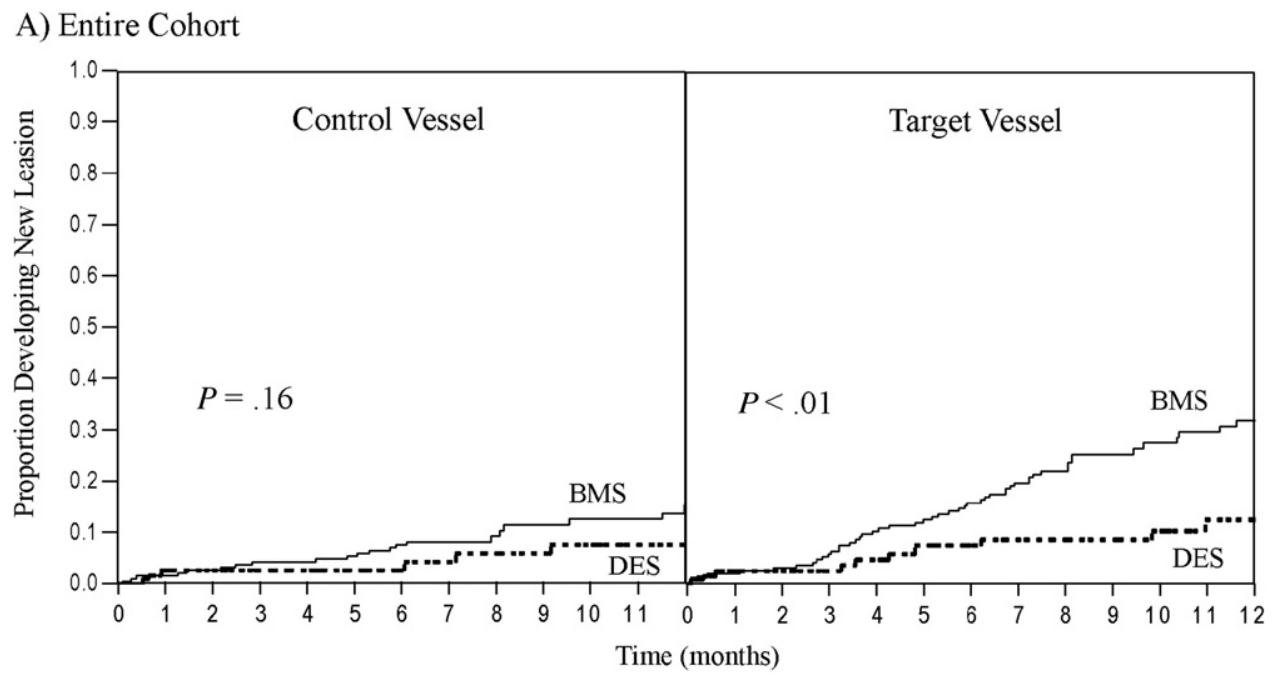

B) Propensity Matched Cohort

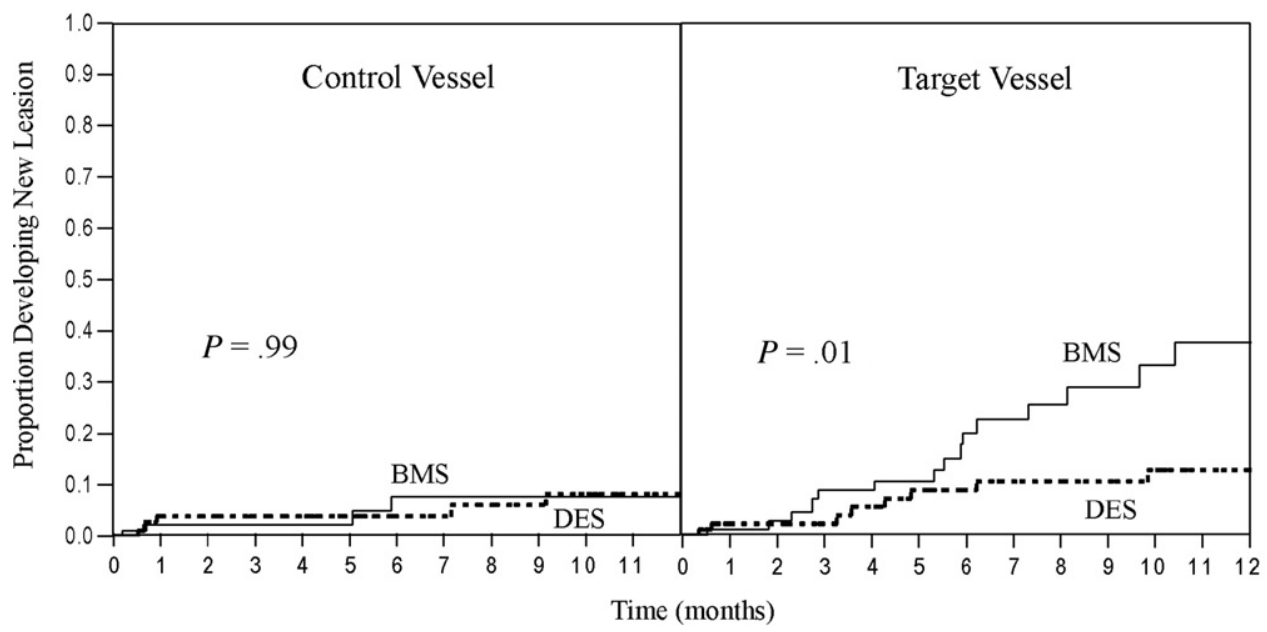

Kaplan-Meier analysis of new lesion development in control and target vessels for both the entire (A) and the propensity-matched (B) cohorts.

Table II. Cox proportional hazard models for development of new lesions and the need for new interventions downstream of stents

\begin{tabular}{|c|c|c|c|c|c|c|}
\hline \multirow[b]{2}{*}{ Variable } & \multicolumn{3}{|c|}{ New lesion } & \multicolumn{3}{|c|}{ New intervention } \\
\hline & HR & $95 \% \mathrm{Cl}$ & $\boldsymbol{P}$ & HR & $95 \% \mathrm{Cl}$ & $\boldsymbol{P}$ \\
\hline Age & 1.02 & $0.99-1.04$ & .15 & 1.01 & $0.99-1.04$ & .38 \\
\hline Systolic blood pressure & 1.00 & $0.99-1.01$ & .79 & 1.00 & $0.99-101$ & .89 \\
\hline Diabetes & 1.39 & $0.82-2.31$ & .21 & 1.43 & $0.83-2.45$ & .20 \\
\hline Smoking history & 1.01 & $0.61-1.68$ & .97 & 0.95 & $0.56-1.61$ & .84 \\
\hline Hyperlipidemia & 0.89 & $0.52-1.50$ & .59 & 0.77 & $0.45-1.37$ & .37 \\
\hline BMl & 0.99 & $0.95-1.04$ & .83 & 1.00 & $0.96-1.05$ & .88 \\
\hline DES & 0.39 & $0.19-0.75$ & $<.01$ & 0.47 & $0.22-0.90$ & .02 \\
\hline
\end{tabular}

not seen in the control vessels, which were exposed to much lower drug concentrations (after major dilutional and clearance mechanisms took effect).

We find it most surprising that the downstream consequences of DES on angiographic lesion development have not been previously directly examined, particularly given countless published studies examining clinical outcomes as well as various basic science investigations of mechanism of action. The current theory of abluminal diffusion directly into the endothelium has taken root as a de facto mechanism of stentbased drug delivery after a variety of animal studies demonstrating high local intravascular concentrations. ${ }^{36}$ This mechanism surely contributes to the prevention of restenosis. However, recent literature has described the mathematical relationships of drug delivery into the 
Figure 3

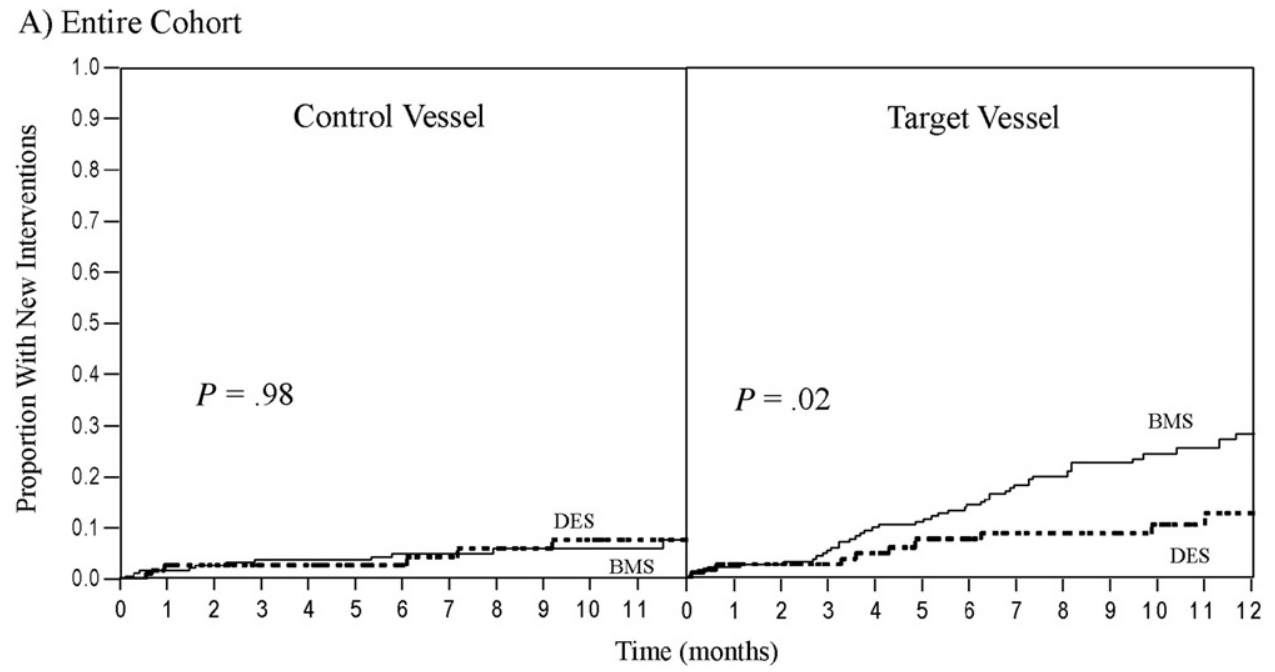

B) Propensity Matched Cohort

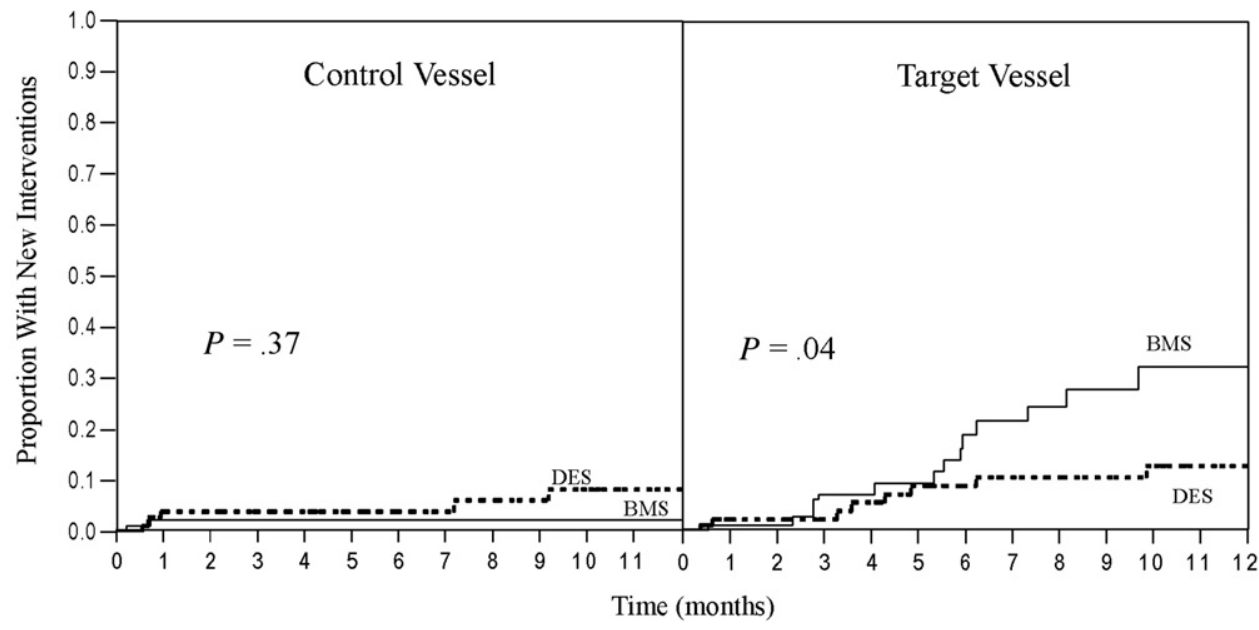

Kaplan-Meier analysis of new interventions in control and target vessels for both the entire (A) and the propensity-matched (B) cohorts.

bloodstream via adluminal mass transfer. In fact, diffusion kinetics modeling of stent struts points toward serum diffusion as an important mechanism of drug delivery into the local endothelium. ${ }^{37,38}$ In addition, oral administration of cell-cycle inhibitors prevent in-stent restenosis as well atherosclerotic progression in heart transplant patients, suggesting that serological delivery of drug, without high tunical concentrations, is able to affect stenotic progression. ${ }^{9,29}$ Downstream endothelial effects should therefore be expected, in addition to effects on circulating macrophages and lymphocytes that are central to the development and progression of atherosclerotic plaques.

The patient population in this study was carefully selected to achieve its objective-assessment of downstream lesion formation and clinical events in patients receiving stents and whether antiproliferative drug delivery could modify this process. This theory came from benchtop research examining the stent as a mechanism of drug delivery. This study was not designed to compare DES and BMS to suggest a clinical benefit of one over another; there are countless other studies with far larger patient populations trying to gain insight into that question. Rather, the nature of patient selection was extremely restricted to minimize other variables that could bias the results. Thus, single primary stent interventions in proximal vessels were selected to minimize the contributions of modified coronary flow and multiple treatments within a given vessel. Disease-free downstream regions were required to ensure recognition of de novo stenoses and not progression of previously existent disease. Fewer de novo events were recognized in 
control vessels, and thus, statistical power was limited in these vessels. Systemic drug delivery also occurs from implanted stents, but it is likely that its impact is far smaller than what is seen in the distal vessel.

Our study has limitations other than just sample size, including the fact that it is observational and thus prone to inherent biases, although attempts were made to adjust for this using multiple analytic techniques. In addition, all interventional registry data were prospectively collected under the supervision of professional staff to ensure completeness and accuracy. In all cases of the variables described, a consistent result was obtained with mandatory quality assurance. This was a single-center cohort collected over a long period and may therefore not be generalizable to all patients; however, correction for time frame showed no difference in results (data not shown). Some data, such as primary lesion length, were not collected for patients enrolled in the early years of this database, and thus, analysis of primary lesions traits is limited. Our cohort was dependent on patients who all required subsequent secondary intervention within a 1-year period. This identified a cohort at increased risk for developing atherosclerotic disease and plaque rupture despite pharmacologic and percutaneous intervention. Whether similar results would be seen in a much broader cohort of patients undergoing coronary intervention remains uncertain.

In summary, we have demonstrated that patients who received a DES at initial coronary intervention had a significant reduction in the risk of new lesion development and were less likely to require a secondary intervention in the downstream target vessel by 12 months. Control vessels did not show any significant difference, suggesting a direct benefit provided by the DES. The implications of these results challenge the biologic and clinical scenarios by which DES are believed to operate. The mechanism for how antiproliferatives inhibit the development of downstream coronary lesions after intervention, however, requires further clarification. In addition, the pharmacokinetics and pharmacodynamics of drug delivery in the downstream coronary should be investigated thoroughly. Although these results demonstrate protection from lesion formation, toxicity of antiproliferative drugs still remains a concern, particularly in tissues affected by infarction because of the potential for inducing a thrombogenic state through platelet dysfunction as well as neoatherosclerosis. ${ }^{18,31,39}$ Despite these uncertainties, our findings should encourage a clinical trial with advanced coronary imaging tools to further investigate the effects that DES have on atherosclerosis in downstream vessels.

\section{Disclosures}

The following authors claim disclosures: Dr Krasuski is on the speaker's bureau, Roche Pharmaceuticals, and is both a consultant for and on the speaker's bureau of
Actelion Pharmaceuticals. Dr Ellis is a paid consultant or speaker for the following companies: Abbott Vascular, BioHeart Inc, Boston Scientific Corp, Cordis Corp, and Viacor, Inc. Dr Nissen reports that he has consulted for the following companies and has them donate all honoraria or consulting fees directly to nonprofit organizations so that he receives neither income nor a tax deduction: Alnylam Pharmaceuticals, AstraZeneca, Boehringer Ingelheim, CSL, Inc, Daiichi-Sankyo, Eli Lilly, Forbes Medi-tech, Forest Laboratories, GlaxoSmithKline, Hoffman-LaRoche, Karo Bio, Novartis, Novo-Nordisk, Pfizer, Resverlogix, Sanofi-Aventis, Takeda, Xoma George Cater; Ganesh Devendra, Kathy Wolski, and Dr Shishehbor have no financial disclosures or conflicts of interest to claim.

Funding Sources: American Heart Association Student Scholarship for Cardiovascular Disease and Stroke.

\section{References}

1. Rensing BJ, Hermans WR, Beatt KJ, et al. Quantitative angiographic assessment of elastic recoil after percutaneous transluminal coronary angioplasty. Am J Cardiol 1990;66:1039-44.

2. Rodríguez $A E$, Palacios IF, Fernández MA, et al. Time course and mechanism of early luminal diameter loss after percutaneous transluminal coronary angioplasty. Am J Cardiol 1995;76:1131-4.

3. Serruys PW, de Jaegere P, Kiemeneij F, et al. A comparison of balloon-expandable-stent implantation with balloon angioplasty in patients with coronary artery disease. Benestent Study Group. N Engl J Med 1994;331:489-95.

4. Kirtane AJ, Gupta A, lyengar S, et al. Safety and efficacy of drugeluting and bare metal stents: comprehensive meta-analysis of randomized trials and observational studies. Circulation 2009;119: 3198-206

5. Ong ATL, Daemen J, van Hout BA, et al. Cost-effectiveness of the unrestricted use of sirolimus-eluting stents vs. bare metal stents at 1 and 2-year follow-up: results from the RESEARCH Registry. Eur Heart J 2006;27:2996-3003.

6. Nikol S, Huehns TY, Höfling B. Molecular biology and postangioplasty restenosis. Atherosclerosis 1996;123:17-31.

7. Suzuki T, Kopia G, Hayashi S, et al. Stent-based delivery of sirolimus reduces neointimal formation in a porcine coronary model. Circulation 2001;104:1188-93.

8. Sousa JE, Costa MA, Abizaid AC, et al. Sustained suppression of neointimal proliferation by sirolimus-eluting stents: one-year angiographic and intravascular ultrasound follow-up. Circulation 2001; 104:2007-11.

9. Rodriguez $A E$, Granada JF, Rodriguez-Alemparte $M$, et al. Oral rapamycin after coronary bare-metal stent implantation to prevent restenosis: the Prospective, Randomized Oral Rapamycin in Argentina (ORAR II) Study. J Am Coll Cardiol 2006;47:1522-9.

10. Waksman $R$, Ajani $A E$, Pichard $A D$, et al. Oral rapamycin to inhibit restenosis after stenting of de novo coronary lesions: the Oral Rapamune to Inhibit Restenosis (ORBIT) study. J Am Coll Cardiol 2004;44:1386-92.

11. Park S, Park D. Percutaneous coronary intervention with stent implantation versus coronary artery bypass surgery for treatment of left main coronary artery disease: is it time to change guidelines? Circ Cardiovasc Interv 2009;2:59-68.

12. Price MJ, Teirstein PS. The off- versus on-label use of medical devices in interventional cardiovascular medicine: clarifying the ambiguity 
between regulatory labeling and clinical decision-making, Part 1: PCl. Catheter Cardiovasc Interv 2008;72:500-4.

13. McFadden EP, Stabile E, Regar E, et al. Late thrombosis in drugeluting coronary stents after discontinuation of antiplatelet therapy Lancet 2004;364:1519-21.

14. Collet J, Aout M, Alantar A, et al. Real-life management of dual antiplatelet therapy interruption: the REGINA survey. Arch Cardiovasc Dis 2009;102:697-710

15. Collet J, Montalescot G, Steg PG, et al. Clinical outcomes according to permanent discontinuation of clopidogrel or placebo in the CHARISMA trial. Arch Cardiovasc Dis 2009;102:485-96.

16. Fuke S, Maekawa K, Kawamoto K, et al. Impaired endothelial vasomotor function after sirolimus-eluting stent implantation. Circ $J$ 2007;71:220-5.

17. Kim JW, Seo HS, Park JH, et al. A prospective, randomized, 6-month comparison of the coronary vasomotor response associated with a zotarolimus- versus a sirolimus-eluting stent: differential recovery of coronary endothelial dysfunction. J Am Coll Cardiol 2009;53:1653-9.

18. Nakazawa G, Otsuka F, Nakano M, et al. The pathology of neoatherosclerosis in human coronary implants bare-metal and drugeluting stents. J Am Coll Cardiol 2011;57:1314-22.

19. Gadioli ALN, Nogueira BV, Arruda RMP, et al. Oral rapamycin attenuates atherosclerosis without affecting the arterial responsiveness of resistance vessels in apolipoprotein E-deficient mice. Braz J Med Biol Res 2009;42:1191-5.

20. Pakala R, Stabile E, Jang GJ, et al. Rapamycin attenuates atherosclerotic plaque progression in apolipoprotein $E$ knockout mice: inhibitory effect on monocyte chemotaxis. J Cardiovasc Pharmacol 2005;46:481-6.

21. Ma KL, Ruan XZ, Powis SH, et al. Anti-atherosclerotic effects of sirolimus on human vascular smooth muscle cells. Am J Physiol Heart Circ Physiol 2007;292:H2721-8.

22. Elloso MM, Azrolan N, Sehgal SN, et al. Protective effect of the immunosuppressant sirolimus against aortic atherosclerosis in apo E-deficient mice. Am J Transplant 2003;3:562-9.

23. Maranhao RC, Tavares ER, Padoveze AF, et al. Paclitaxel associated with cholesterol-rich nanoemulsions promotes atherosclerosis regression in the rabbit. Atherosclerosis 2008;197:959-66.

24. Douglas PS, Brennan JM, Anstrom KJ, et al. Clinical effectiveness of coronary stents in elderly persons: results from 262,700 Medicare patients in the American College of Cardiology-National Cardiovascular Data Registry. J Am Coll Cardiol 2009;53:1629-41.

25. Neyt $M$, Van Brabandt $H$, Devriese $S$, et al. Cost-effectiveness analyses of drug eluting stents versus bare metal stents: a systematic review of the literature. Health Policy 2009;91:107-20.

26. Rahel BM, Laarman GJ, Kelder JC, et al. Three-year clinical outcome after primary stenting of totally occluded native coronary arteries: a randomized comparison of bare-metal stent implantation with sirolimus-eluting stent implantation for the treatment of total coronary occlusions (Primary Ste. Am Heart J 2009;157:149-55.

27. Brar SS, Leon MB, Stone GW, et al. Use of drug-eluting stents in acute myocardial infarction: a systematic review and meta-analysis. J Am Coll Cardiol 2009;53:1677-89.

28. Oberti C, Navia J, Krasuski R. Apparatus and Method for Treating Cardiovascular Diseases. United States Patent Application Pub. No. 20090177262, July 9, 2009.

29. Keogh A, Richardson M, Ruygrok P, et al. Sirolimus in de novo heart transplant recipients reduces acute rejection and prevents coronary artery disease at 2 years: a randomized clinical trial. Circulation 2004; 110:2694-700.

30. Schmauss $D$, Weis M. Cardiac allograft vasculopathy: recent developments. Circulation 2008;117:2131-41.

31. Wilson GJ, Nakazawa G, Schwartz RS, et al. Comparison of inflammatory response after implantation of sirolimus- and paclitaxel-eluting stents in porcine coronary arteries. Circulation. 2009;120:141-9, 1-2.

32. Vetrovec GW, Rizik D, Williard C, et al. Sirolimus PK trial: a pharmacokinetic study of the sirolimus-eluting Bx velocity stent in patients with de novo coronary lesions. Catheter Cardiovasc Interv 2006;67:32-7.

33. McKeage K, Murdoch D, Goa KL. The sirolimus-eluting stent: a review of its use in the treatment of coronary artery disease. Am J Cardiovasc Drugs 2003;3:211-30.

34. CYPHER sirolimus-eluting coronary stent instructions for use.pdf. Accessed February 6, 2010. Available at http://www. cordislabeling.com/pdf/9578500_11.pdf.

35. Katoh $\mathrm{H}$, Shite J, Shinke T, et al. Delayed neointimalization on sirolimus-eluting stents: 6-month and 12-month follow up by optical coherence tomography. Circ J 2009;73:1033-7.

36. Levin $A D$, Vukmirovic $N$, Hwang $C$, et al. Specific binding to intracellular proteins determines arterial transport properties for rapamycin and paclitaxel. Proc Natl Acad Sci USA 2004;101: 9463-7.

37. Balakrishnan B, Tzafriri AR, Seifert P, et al. Strut position, blood flow, and drug deposition: implications for single and overlapping drugeluting stents. Circulation 2005;111:2958-65.

38. Balakrishnan B, Dooley JF, Kopia G, et al. Intravascular drug release kinetics dictate arterial drug deposition, retention, and distribution. J Control Release 2007;123:100-8.

39. Pires NMM, Eefting $D$, de Vries MR, et al. Sirolimus and paclitaxel provoke different vascular pathological responses affer local delivery in a murine model for restenosis on underlying atherosclerotic arteries. Heart 2007;93:922-7. 


\section{Appendix}

Supplementary Table I. Control vessel determination

\begin{tabular}{|c|c|c|}
\hline Stent Vessel & $\begin{array}{c}\text { Control Vessel } \\
\text { option } 1\end{array}$ & $\begin{array}{c}\text { Control Vesse } \\
\text { option } 2\end{array}$ \\
\hline Proximal LAD & Proximal Circ & Proximal RCA \\
\hline Mid LAD & Mid Circ & Mid RCA \\
\hline Proximal Circ & Proximal LAD & Proximal RCA \\
\hline Mid Circ & Mid LAD & Mid RCA \\
\hline $\begin{array}{c}\text { Circ AV Groove } \\
\text { Continuation }\end{array}$ & Distal RCA & none \\
\hline Proximal RCA & Proximal LAD & Proximal Circ \\
\hline Mid RCA & Mid LAD & Mid Circ \\
\hline Distal RCA & $\begin{array}{c}\text { Circ AV Groove } \\
\text { Continuation }\end{array}$ & none \\
\hline
\end{tabular}

Supplementary Calculation: Coronary AUC Concentration Calculation.

No study has directly measured coronary concentrations of drug delivered from DES, though product labeling provides area under the concentration time curves (AUC) for venous concentrations of Cypher stents in humans. Our estimates of intra-coronary AUC are based upon the proportion of flow through the coronary arteries and the venous AUC. Typical blood flow to a single coronary artery is approximately $4 \%$ of the cardiac output, and the venous AUC is recorded as
$127 \mathrm{ng} * \mathrm{hr} / \mathrm{ml}$. Assuming that this $4 \%$ of blood flow is providing drug to the entire systemic circulation, it would be expected that the AUC of the coronary is 3175 $\mathrm{ng} * \mathrm{hr} / \mathrm{ml}$ (see supplemental calculation). It therefore seems very likely that the downstream coronary arteries are exposed to concentrations significantly higher than those recognized in the venous blood, levels that are sufficient for therapeutic inflammatory modulation within the vascular wall.

Variables

Dose $=$ total amount of drug delivered

Vd_sys = systemic volume of distribution

Vd_coronary $=$ coronary delivered volume of distribution

Vd_coronary $=0.04 * \mathrm{Vd} \_$system

AUC_system = systemic measured AUC $=127 \mathrm{ng} * \mathrm{hg} / \mathrm{ml}$ AUC_coronary = coronary AUC to be determined

GOVERNING EQUATION : Dose $=\mathrm{Vd} *$ AUC $*$ Elimination

- Dose and elimination remains constant between coronary and system

DOSE $=$ Vd_system $*$ AUC_system $*$ Elimination $=$

Vd_coronary $*$ AUC_coronary $*$ Elimination

Vd_system $*$ AUC_system $=$ Vd_coronary $*$

AUC_coronary

Vd_system $*$ AUC_system $=0.04 * V d \_s y s t e m *$

AUC_coronary

25* AUC_system = AUC_coronary

$25 * 127 \mathrm{ng} * \mathrm{hr} / \mathrm{ml}=$ AUC_coronary $=3175 \mathrm{ng} * \mathrm{hr} / \mathrm{ml}$

\section{Supplementary Figure 1}

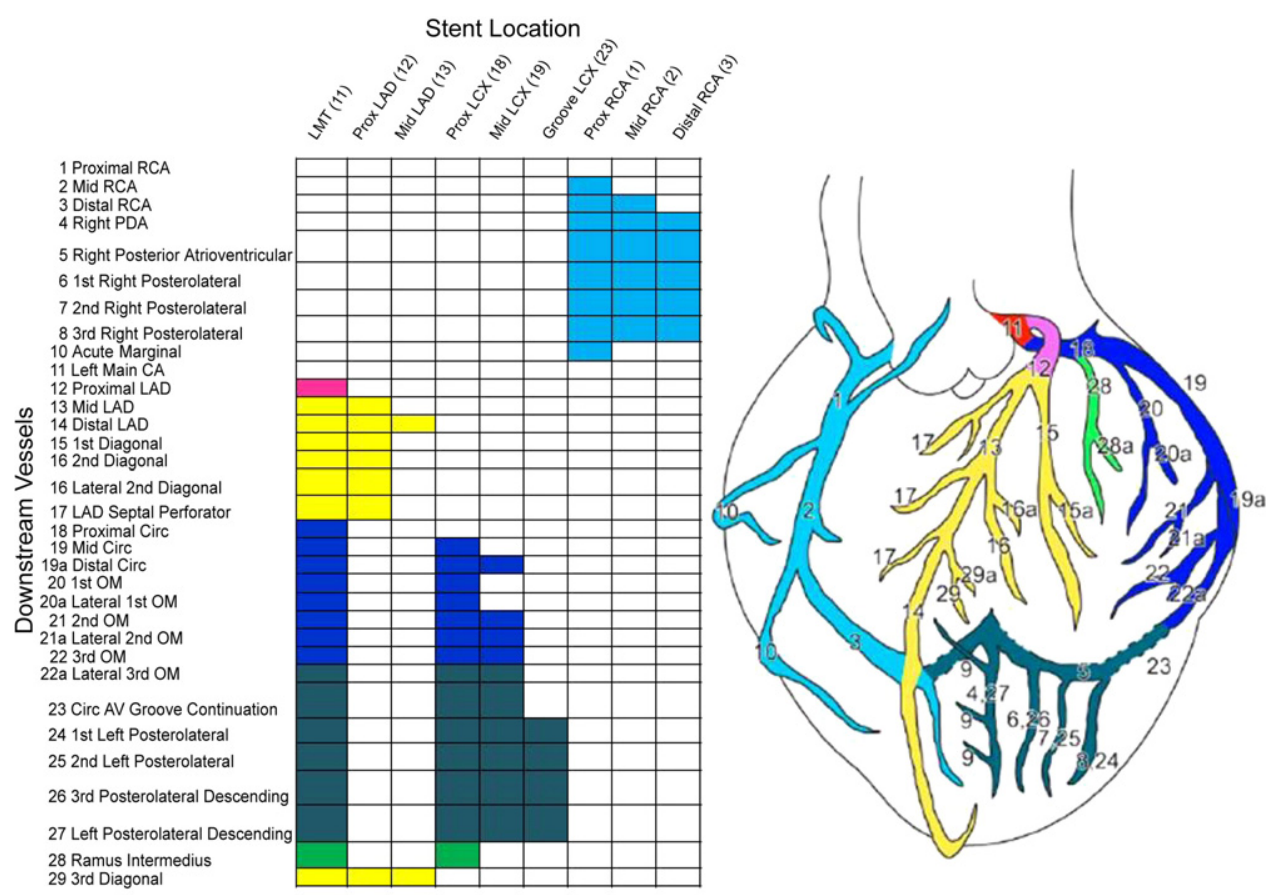

Downstream vessel determination. 